\title{
Prevalence and socio-demographic factors associated with physical inactivity among primary health care users in Tirana, Albania: A cross-sectional study
}

\author{
Aldo Shpuza*, Xhesika Xhetani \\ Department of Public Health, University of Medicine, Tirane, Albania
}

\begin{abstract}
Introduction: The World Health Organization (WHO) defines physical activity (PA) as any movement of the body produced by skeletal muscle that requires expenditure of energy. The aim of research is to assess the prevalence of and socio-demographic characteristics associated with physical inactivity (PI) among adult primary healthcare (PHC) users in Tirana, the capital of Albania.

Methods: This was a cross-sectional study carried out in Tirana from November 2020 to January 2021. During this period 500 consecutively approached individuals aged $\geq 18$ years exiting PHC centers were interviewed face-to-face about the presence of some of the risk factors for non-communicable disease. A structured WHO STEPS questionnaire, an integrated part of which is the instrument required for this study, "Global PA Questionnaire," was used. In addition to demographic and socioeconomic data, we obtained data on the performance of PA in terms of domains, duration, and intensity. Logistic regression was used to assess socio-demographic factors associated with PI.

Results: Prevalence of Pl in the study population was 31.6\%. Following multivariable adjustment for all covariates, significant positive correlates of PI were female gender, rural residence, retiree status, and unemployment. Conversely, there was an inverse association with moderate level of education.

Conclusions: Similar to that of other European populations, the population of Tirana has a high rate of PI showing an upward tendency. The population groups at the highest risk of PI who may be targeted for intervention programs to address this risk factor are women, rural residents, unemployed persons, and retirees.

Keywords: Physical inactivity; physical activity levels; prevalence; socio-demographic factors; non-communicable diseases; Albania
\end{abstract}

\section{INTRODUCTION}

The World Health Organization (WHO) defines physical activity (PA) as "any movement of the body produced by skeletal muscle that requires expenditure of energy" (1). The scope of the present study determines the need to categorize different levels of $\mathrm{PA}$, with a focus on physical inactivity (PI). PI is defined as inadequate PA, "in other words," failure to meet specified PA recommendations (2). Regular PA is considered a protective factor for the prevention and treatment of many non-communicable diseases (NCDs) such as cardiovascular disease, stroke, diabetes, and breast and colon cancer (3-5). Conversely, scientific evidence shows that PI increases the risk of many of the aforementioned NCDs and contributes to reduced life expectancy $(6,7)$.

*Corresponding author: Aldo Shpuza, Department of Public Health, University of Medicine, Rruga e Dibres 371, Tirana, Albania.

E-mail: aldoshpuza@hotmail.com

Submitted: 27 August 2021/Accepted: 14 December 2021

DOI: https://doi.org/10.17532/jhsci.2021.1474
Monitoring and surveillance of PA are important aspects that are integrated into the development of health policies in long-term plans, such as the achievement of the 2030 Sustainable Development Goals and WHO Global PA Action Plan 2018-2030 (8). According to data from 168 different countries in 2016, the global prevalence of PI was $27.5 \%$ (confidence interval [CI] 95\% 25.0-32.2), with a difference of more than $8 \%$ between men $(23.4 \%, 21.1-30.7)$ and women (31.7\%, 28.6-39.0) (9). According to the WHO, PI ranks fourth among global mortality risk factors, accounting for $6 \%$ of global mortality. While the prevalence of PI is higher in high-income countries, low- and middle-income countries still bear most of the global PI-related morbidity (9). Differences in levels of PA are also affected by gender, social inequalities, or differences between countries (10). Women, elderly persons, people with low socioeconomic status, chronic patients, marginalized people, or rural populations often have less access to safe, accessible, and affordable spaces for PA (8). 
If we look back on previous data, a significant decline is apparent in age-related PA levels (11). Closing the gender gap in PA levels is also important because women continue to have low levels of PA (12). A positive relationship between unemployment and PI is also well documented, as is a relationship between low level of education and PI $(13,14)$.

Albania, a former communist country in Southeast Europe, has undergone an economic transition and, since 2009 , has been considered an upper-middle-income country (15). At the same time, the epidemiological transition is characterized by a significant increase in the burden of NCDs and associated risk factors such as tobacco use, alcohol consumption, PI, and unhealthy diet (16). Although Albania has integrated a screening program for NCDs and associated risk factors into primary health care (PHC), little information is available on the PA levels of the population (17). Therefore, the objective of this study is to provide an overview of the profile of the physically inactive population and enable policymakers to establish NCD prevention response programs.

\section{METHODS}

This cross-sectional study was carried out in Tirana, the capital of Albania, between November 2020 and January 2021.

The target population of the study was PHC users aged over 18 years of age or older.

The study was conducted in the Tirana Region, which accounts for approximately one-third of the Albanian population (18). We randomly selected two health centers (HCs), in two different administrative units, in urban Tirana, HC No. 7, and in rural Kamez, HC Paskuqan. Assuming the highest proportion (50\%), 95\% CI, and margin of error of 5\%, an initial sample size of 384 individuals was calculated, but in order to adjust for the anticipated $20 \%$ non-response rate and to increase the power of the study, a sample size of 500 individuals was estimated. To be included in the study, individuals exiting the selected HCs after attending the service had to: a) be 18 years of age or older and b) givewritten informed consent.

In total, 726 of the individuals were invited to partake in the study, and 500 individuals were interviewed, (250 at urban HC Nr.7 Tirane, 250 at rural HC Paskuqan, Kamez).

There were no significant gender differences between respondents and non-respondents $(p=0.7)$.

The survey instrument (questionnaire) was applied consecutively to individuals who attended the service and exited the health care facilities until the predefined number of questionnaires was reached. The data collection consisted of a face-to-face interview conducted through the WHOSTEPS instrument (questionnaire) for the monitoring of NCD risk factors, an integrated part of which is extracted data on PA. The Global PA Questionnaire (GPAQ) is an internationally validated instrument (10). The questionnaire was translated into Albanian and back translated into English for possible adaptations and tested on a sample of 30 individuals who were not part of the study sample. The instrument guaranteed face validity and content validity. The GPAQ assesses the frequency and duration of PA in three domains: at work, in transportation, and in leisure or recreational activities. Data were collected through interviews conducted by public health students, trained 2 days in advance.

The variables included socio-demographic characteristics: gender, age (categorized into 18-34 years, 35-65 years and $\geq 66$ years), education (categorized into low, medium, and high), employment status (categorized into employed, unemployed, and retired), place of residence (urban vs. rural areas), marital status (categorized into never married, married, and formerly married) and economic status (categorized into low, moderate, and high).

PA is categorized into low PA, moderate PA, and high PA, based on the recommendations of the WHO STEPS manual (19). To meet all the definitions of the three categories of PA, we calculated the metabolic equivalent of task (MET)-minutes in advance, and then we selected the cases, according to the cut-offs of MET-minutes, cut-offs of the number of days per week, and cut-offs of the number of minutes per day in which participants engaged in intense, moderate PA or walking/pedaling, respectively for each PA category. Then, we recategorized PA into "PI" and "moderate/high PA."

Descriptive statistics were used to report frequency, percentages, mean, standard deviation, and interquartile range.

Binary logistic regression was used to assess the association of levels of PA with socio-demographic characteristics. Crude (unadjusted) odds ratios (OR: "PI" vs. "High/moderate PA") and their respective 95\% CIs were calculated. Subsequently, multivariable-adjusted ORs and their respective 95\% CIs were calculated. A HosmerLemeshow test was used to assess the overall goodnessof-fit of the logistic regression models (all the reported models met the goodness-of-fit criterion).

All data analyses were performed using the Statistical Package for Social Sciences, statistical software, version 25.0.

All participants in the study were informed about the purpose and objectives of the study.

Participation was assured both confidentiality and privacy. Written consent for participants was obtained confirming their voluntary participation and the right to withdraw from the study at any time. An approval letter from the Ethics Committee at the Ministry of Health and Social Protection was received for the study on NCDs risk factors and primary care, as a part of which this study was compiled.

\section{RESULTS}

Table 1 presents the characteristics of the sample.

The sample of the study consisted of 500 individuals over the age of 18 (of whom $58.8 \%$ were female, and $41.2 \%$ were male). The mean age of the study population was 49.2 ( $\mathrm{SD}=16.6)$. The study population consisted of equal shares of rural and urban residents. Thirty-two percent 
TABLE 1. Distribution of socio-demographic characteristics and PI prevalence among adult primary health care users. Absolute numbers and their respective row percentages

\begin{tabular}{|c|c|c|}
\hline Variables & Total (\%) & $\mathrm{Pl}^{*}(\%)$ \\
\hline \multicolumn{3}{|l|}{ Sex: } \\
\hline Men & $206(41.2)$ & $58(28.2)$ \\
\hline Women & $294(58.8)$ & $100(34.0)$ \\
\hline \multicolumn{3}{|l|}{ Age-group } \\
\hline $18-34$ & $116(32.0)$ & $22(19.0)$ \\
\hline $35-65$ & $289(42.4)$ & $90(31.1)$ \\
\hline$>66$ & $95(25.6)$ & $46(48.4)$ \\
\hline \multicolumn{3}{|l|}{ Residence } \\
\hline Urban & $250(50)$ & $64(25.6)$ \\
\hline Rural & $250(50)$ & $94(37.6)$ \\
\hline \multicolumn{3}{|l|}{ Employment } \\
\hline Yes & $160(32.0)$ & $23(14.4)$ \\
\hline No & $212(42.4)$ & $74(34.9)$ \\
\hline Retiree & $128(25.6)$ & $61(47.7)$ \\
\hline \multicolumn{3}{|l|}{ Education } \\
\hline Low & $239(47.8)$ & $103(43.1)$ \\
\hline Moderate & $144(28.8)$ & $33(22.9)$ \\
\hline High & $117(23.4)$ & $22(18.8)$ \\
\hline \multicolumn{3}{|l|}{ Marital status } \\
\hline Not married & $72(14.4)$ & $12(16.7)$ \\
\hline Married & $387(74.4)$ & $124(32.0)$ \\
\hline Formerly married & $41(8.2)$ & $22(53.7)$ \\
\hline \multicolumn{3}{|l|}{ Economic status } \\
\hline Low & $84(16.8)$ & $31(36.9)$ \\
\hline Moderate & $346(69.2)$ & $111(32.1)$ \\
\hline High & $70(14.0)$ & 16 (22.9) \\
\hline
\end{tabular}

*Pl: Physical inactivity

of individuals were employed; $42.4 \%$ of individuals were unemployed; and $25.6 \%$ of individuals were retired. Most respondents reported being married $(74.4 \%)$, moderately well off (69.2\%), and poorly educated (47.8\%) (Table 1).

Overall, the prevalence of PI in the study population was 31.6\% (95\% CI: 27.5-35.9). PI was more prevalent among women, individuals over 65-years-old, residents of rural areas, retirees and non-employed persons, less-educated individuals, married persons and moderately well-off individuals (Table 1 ).

Mean sitting time per day was $189.5 \mathrm{~min}$ (95\% CI: 181.2 197.9), and the median was $180 \mathrm{~min}$ (IQR: 120-240); $2.4 \%$ (95\% CI: $1.2-4.2)$ of individuals spent more than $8 \mathrm{~h} /$ day sitting.

Among the study population, $76.2 \%$ did not engage in moderate/vigorous PA at work, while $80.6 \%$ did not participate in moderate/vigorous PA during their leisure time.

Table 2 demonstrates the crude and adjusted ORs of covariates.

In general, the crude (unadjusted) OR of PI were higher among: women (vs. men: $[\mathrm{OR}=1.32,95 \% \mathrm{CI}=0.89$ 1.94]), individuals over 65-years-old (vs. individuals 18-34-years-old: [OR $=4.01,95 \% \mathrm{CI}=2.17-7.41]$ ), individuals 35-65-years-old (vs. individuals 18-34-years-old: $[\mathrm{OR}=1.93,95 \% \mathrm{CI}=1.14-3.27]$ ), rural residents (vs. urban residents $[\mathrm{OR}=1.75,95 \% \mathrm{CI}=1.20-2.57]$ ), retirees (vs. employed persons $[\mathrm{OR}=5.42,95 \% \mathrm{CI}=3.09-9.51]$ ), unemployed persons (vs. employed persons [OR $=3.19$, 95\% CI $=1.89-5.40]$ ), formerly married persons (vs. not married persons $[\mathrm{OR}=5.79,95 \% \mathrm{CI}=2.42-13.85]$ ) and married persons (vs. unmarried persons $[\mathrm{OR}=2.36,95 \%$ $\mathrm{CI}=1.22-4.54])$. Conversely, lower crude (unadjusted) odds of PI were observed among individuals with higher education levels (vs. individuals with lower education levels): $[\mathrm{OR}=0.31,95 \% \mathrm{CI}=0.18-0.52])$, individuals with moderate education levels (vs. individuals with low education levels: $[\mathrm{OR}=0.39,95 \% \mathrm{CI}=0.25-0.63])$ and the wealthiest persons (vs. poorest persons: $[\mathrm{OR}=0.51,95 \%$ $\mathrm{CI}=0.25-1.03])$.

On multivariable adjustment for all covariates, significant positive correlates of PI were female gender (vs. male gender: $[\mathrm{OR}=1.66,95 \% \mathrm{CI}=1.06-2.59]$ ), rural residence (vs. urban residence $[\mathrm{OR}=1.75,95 \% \mathrm{CI}=1.12-2.74]$ ), retiree status (vs. employment $[\mathrm{OR}=3.28,95 \% \mathrm{CI}=1.45-7.43]$ and unemployment (vs. employment $[\mathrm{OR}=2.33,95 \%$ $\mathrm{CI}=1.45-7.43]$ ). However, lower odds of PA persisted upon multivariable adjustment for all covariates in individuals with moderate education levels (vs. individuals with lower education levels: $[\mathrm{OR}=0.58,95 \% \mathrm{CI}=0.35-0.95]$ ) (Table 2).

\section{DISCUSSION}

The prevalence of PI in the adult population of Tirana was higher than the global prevalence of PI, albeit within the CI of the latter (31.6\% [95\% CI: 27.5-35.9] vs. $27.6 \%$ [95\% CI 25.0-32.2], respectively) (9). As for the population of Tirana, PI as a risk factor affects approximately 300,000 persons (11). On the basis of the above, a comparison of overall levels of PA in 28 European countries showed a prevalence of $36.2 \%$ (95\% CI: 35.1-37.3), wherein Southern and Eastern Europe recorded the highest levels of PI in comparison with Western and Northern Europe, which reinforces our findings about the PI of the population of Tirana, located in Southeast Europe (20).

Focusing on the major domains in which individuals engage in PA or are exposed to the risk factor (PI), we found the prevalence of PI at work and during leisure to be relatively high, $76.2 \%$ and $80.6 \%$, respectively. In a similar study in India, about $90 \%$ of people did not engage in enough PA during their leisure time, while PA at work was higher than during leisure time (21).

The socio-demographic factors significantly associated with PI in the study population were female gender, rural residence, unemployment, and retiree status.

Meanwhile, moderate education level reflected a lower likelihood of PI.

There was a considerable difference in PI between women and men (34\% vs. $28.2 \%)$, and the gender differences in the likelihood of PI were significant after adjusting for covariates $(\mathrm{OR}=1.66,95 \% \mathrm{CI}=1.06-2.59)$. A study conducted in Tirana in 2001 showed that $28.4 \%$ of women and $19.3 \%$ of men did not engage in enough PA (22). While the male-female ratio has been maintained, the percentages show a growing trend over the years of PI among both sexes. Though the PI urban-rural differences differ from country to country in favor of rural settlements, as is the case in our study, in many other European countries, this gap has 
TABLE 2. Socio-demographic factors associated with Physical inactivity

\begin{tabular}{|c|c|c|c|c|}
\hline \multirow[t]{2}{*}{ Socio-demographic factors } & \multicolumn{2}{|c|}{ Crude (unadjusted) models } & \multicolumn{2}{|c|}{ Multivariable-adjusted models } \\
\hline & $\mathrm{OR}^{*}$ & $95 \%(\mathrm{Cl})^{*}$ & OR & $95 \%(\mathrm{Cl})$ \\
\hline \multicolumn{5}{|l|}{ Sex } \\
\hline Males & 1.00 & Reference & 1.00 & Reference \\
\hline Females & 1.32 & $0.89-1.94$ & 1.66 & $1.06-2.59$ \\
\hline \multicolumn{5}{|l|}{ Age-group } \\
\hline $18-34$ & 1.00 & Reference & 1.00 & Reference \\
\hline $35-65$ & 1.93 & $1.14-3.27$ & 1.50 & $0.76-2.96$ \\
\hline$>66$ & 4.01 & $2.17-7.41$ & 2.07 & $0.72-5.97$ \\
\hline \multicolumn{5}{|l|}{ Residence } \\
\hline Urban & 1.00 & Reference & 1.00 & Reference \\
\hline Rural & 1.75 & $1.20-2.57$ & 1.75 & $1.12-2.74$ \\
\hline \multicolumn{5}{|l|}{ Employment } \\
\hline Yes & 1.00 & Reference & 1.00 & Reference \\
\hline No & 3.19 & $1.89-5.40$ & 2.33 & $1.35-4.05$ \\
\hline Retiree & 5.42 & $3.09-9.51$ & 3.28 & $1.45-7.43$ \\
\hline \multicolumn{5}{|l|}{ Education } \\
\hline Low & 1.00 & Reference & 1.00 & Reference \\
\hline Moderate & 0.39 & $0.25-0.63$ & 0.58 & $0.35-0.95$ \\
\hline High & 0.31 & $0.18-0.52$ & 0.61 & $0.31-1.20$ \\
\hline \multicolumn{5}{|l|}{ Marital status } \\
\hline Not married & 1.00 & Reference & 1.00 & Reference \\
\hline Married & 2.36 & $1.22-4.54$ & 0.95 & $0.41-2.19$ \\
\hline Formerly married & 5.79 & $2.42-13.85$ & 1.33 & $0.45-3.90$ \\
\hline \multicolumn{5}{|l|}{ Economic status } \\
\hline Low & 1.00 & Reference & 1.00 & Reference \\
\hline Moderate & 0.81 & $0.49-1.33$ & 0.96 & $0.55-1.67$ \\
\hline High & 0.51 & $0.25-1.03$ & 0.72 & $0.32-1.61$ \\
\hline
\end{tabular}

${ }^{*}$ Odd ratios (OR: Physical inactivity vs. Moderate/high Physical activity), 95\% confidence intervals $(95 \% \mathrm{Cl}$ ) from binary logistic regression

started to disappear with an increase in the prevalence of PI, irrespective of the level of urbanization (23-25). In terms of employment status, unemployed persons and retirees were more likely to be physically inactive than employees. The importance of employment as a determinant of PA was also noted in a study in the United States that showed that individuals employed even in jobs that involved sedentary behaviors have higher levels of PA than unemployed persons (26). In a study carried out in the Netherlands, individuals with low educational levels were more likely to reduce their level of PA than individuals with high levels of educational attainment (13). With this relationship expressed as an inverse association, the study conducted in our country found a lower likelihood of PI among those with moderate education levels.

Higher age, lower education, and low income are factors that interfere with participation in high levels of PA (27). Our univariate analysis also indicates insufficient activity on the part of the same groups, although age and economic level do not remain significant after a multivariable adjustment.

It is important to be aware of the barriers that prevent these target groups from exercising on a regular and adequate basis. Barriers such as lack of time, cost, motivation, or lack of infrastructure affect all socio-demographic factors, despite different proportions among groups (28). As a result, gender, age, and socioeconomic gaps translate into different levels of PA. Overall, national and international policies to eliminate PI appear to have led to modest increases in levels of PA (29). The high prevalence of PI should serve as an alert to improve the effectiveness of the screening program and take further interventions to reduce this risk factor.

This study has some limitations.

The period of data collection (November 2020-January 2021) corresponded to the progression of the COVID-19 epidemic in Albania. It is not to be excluded that isolation measures related to the COVID-19 pandemic in our country, such as quarantines and physical distancing, have had an impact on people's opportunities for PA. Some studies have shown a significant reduction in PA engagement and a marked increase in sedentary behaviors compared to pre-pandemic levels $(30,31)$. This can affect the overestimate of the prevalence of PI during the data-collection period; however, it can be useful for future studies comparing PA levels and the impact of the pandemic on this factor. This study relies on the report of individuals using PHC; therefore, it cannot be generalized to the entire adult population of Tirana. The risk of recall bias, intentional or unintentional, should be considered while interpreting the results. By referring to the consecutive exit interview of individuals who accessed health care, selection bias cannot be excluded. This study cannot infer causality due to cross-sectional design.

\section{CONCLUSION}

Similar to other European populations, the population of Tirana has a high rate of PI, showing an upward tendency. A high percentage of lack of PA (moderate/high) 
occurs through PA at work or during leisure time. Our study focuses on certain demographic and socioeconomic correlates that have significantly increased the likelihood of not engaging in enough PA. Thus, the population groups at the highest risk of PI that may be targeted for intervention programs to address this risk factor are women, rural residents, unemployed persons, and retirees. PI, as one of the main drivers of NCDs, should receive more attention from policymakers' intent on reducing it and promoting PA among the population.

\section{CONFLICTS OF INTEREST}

No conflict of interest to declare.

\section{REFERENCES}

1. Physical Activity; 2021. Available from: https://www.who.int/news-room/fact-sheets/ detail/physical-activity [Last accessed on 2021 Jul 21].

2. Tremblay MS, Aubert S, Barnes JD, Saunders TJ, Carson V, Latimer-Cheung AE et al. Sedentary behavior research network (SBRN)-terminology consensus project process and outcome. Int J Behav Nutr Phys Act 2017;14(1):75.

3. Li J, Siegrist J. Physical activity and risk of cardiovascular disease-a meta-analysis of prospective cohort studies. Int J Environ Res Public Health 2012;9(2):391-407. https://doi.org/10.3390/ijerph9020391

4. Physical Activity; 2021. Available from: https:/www.who.int/news-room/fact-sheets/ detail/physical-activity [Last accessed on 2021 Apr 17]

5. Briazgounov IP. The role of physical activity in the prevention and treatment of noncommunicable diseases. World Health Stat Q 1988;41(3-4):242-50.

6. Lee IM, Shiroma EJ, Lobelo F, Puska P, Blair SN, Katzmarzyk PT, et al. Effect of physical inactivity on major non-communicable diseases worldwide: An analysis of burden of disease and life expectancy. Lancet 2012;380(9838):219-29.

https://doi.org/10.1016/S0140-6736(12)61031-9

7. Lee IM, Shiroma EJ, Lobelo F, Puska P, Blair SN, Katzmarzyk PT. Impact of physical inactivity on the world's major non-communicable diseases. Lancet 2012;380(9838):219-29.

8. Global Action Plan on PA 2018-2030: More Active People for a-World Health Organization-Google Books; 2021. Available from: https://www.books.google.al/ books?hl=en\&lr=\&id=rnoydwaaqbaj\&oi=fnd\&pg=pa48\&ots=gpctu9pb- $\&$ \&ig $=k w-$ po19xfhzhvr91qc k0tqdle3a\&redir esc=y $\# v=o n e p a g e \& q \&=$ false [Last accessed on 2021 Apr 30]

9. Guthold R, Stevens GA, Riley LM, Bull FC. Worldwide trends in insufficient physical activity from 2001 to 2016: A pooled analysis of 358 population-based surveys with 1.9 million participants. Lancet Glob Health 2018;6(10):e1077-86.

https://doi.org/10.1016/S2214-109X(18)30357-7

10. Chastin S, van Cauwenberg J, Maenhout L, Cardon G, Lambert EV, van Dyck D. Inequality in physical activity, global trends by income inequality and gender in adults. Int J Behav Nutr Phys Act 2020;17(1):142.

https://doi.org/10.1186/s12966-020-01039-x

11. Sun F, Norman IJ, While AE. Physical activity in older people: A systematic review. BMC Public Health 2013;13:449.

https://doi.org/10.1186/1471-2458-13-449

12. The Lancet Public Health. Time to tackle the physical activity gender gap. Lancet Public Health 2019;4(8):e360. https://doi.org/10.1016/S2468-2667(19)30135-5

13. Droomers M, Schrijvers CT, Mackenbach JP. Educational level and decreases in leisure time physical activity: Predictors from the longitudinal GLOBE study. J Epidemiol Community Health 2001;55(8):562-8. https://doi.org/10.1136/jech.55.8.562

14. Gough M. A couple-level analysis of participation in Physical activity during unemployment. SSM Popul Health 2017;3:294-304.

https://doi.org/10.1016/j.ssmph.2017.03.001

15. Doe J. Political and Economic Situation. Eurydice-European Commission; 2017. Available from: $\quad$ https://www.eacea.ec.europa.eu/national-policies/eurydice content/political-and-economic-situation_en [Last accessed on 2021 Jan 20].

16. Burazeri G, Achterberg P. Health Status in the Transitional Countries of South Eastern Europe (Editorial). SEEJPH. 2015: 1-5.

https://doi.org/10.12908/seejph-2014-43

17. "Si Je?"-Kontrolli Mjekësor Bazë, Ministria e Shëndetësisë; 2021. Available from: https://www.shendetesia.gov.al/si-je-nje-tjeter-hap-strategjik-drejt-rilindjes-qe-duam-2 [Last accessed on 2021 Jan 20].

18. Population of Albania 1 January 2020 INSTAT; 2020. Available from: http://www. instat.gov.al/media/6850/population-on-1-january-2020__ pdf [Last accessed on 2021 Feb 18].

19. The WHO STEPwise Approach to Non-communicable Disease Risk Factor Surveillance; 2021. Available from: https://www.who.int/ncds/surveillance/steps/ steps_manual.pdf [Last accessed on 2021 Jan 14].

20. Nikitara K, Odani S, Demenagas N, Rachiotis G, Symvoulakis E, Vardavas C. Prevalence and correlates of physical inactivity in adults across 28 European countries. Eur J Public Health 2021;31(4):840-5.

https://doi.org/10.1093/eurpub/ckab067

21. Anjana RM, Pradeepa R, Das AK, Deepa M, Bhansali A, Joshi SR, et al. PA and inactivity patterns in India-results from the ICMR-INDIAB study (Phase-1) [ICMRINDIAB-5]. Int J Behav Nutr Phys Act 2014;11:26

https://doi.org/10.1186/1479-5868-11-26

22. Shapo L, Pomerleau J, McKee M. Physical Inactivity in a country in transition: A population-based survey in Tirana city, Albania. Scand J Public Health 2004;32(1):60-7. https://doi.org/10.1080/14034940310011801

23. Martin SL, Kirkner GJ, Mayo K, Matthews CE, Durstine JL, Hebert JR. Urban, rural, and regional variations in physical activity. J Rural Health 2005;21(3):239-44. https://doi.org/10.1111/j.1748-0361.2005.tb00089.x

24. Parks SE, Housemann RA, Brownson RC. Differential correlates of physical activity in urban and rural adults of various socioeconomic backgrounds in the United States. J Epidemiol Community Health 2003:57(1):29-35 https://doi.org/10.1136/jech.57.1.29

25. Moreno-Llamas A, García-Mayor J, de la Cruz-Sánchez E. Urban-rural differences in trajectories of PA in Europe from 2002 to 2017. Health Place 2021;69:102570. https://doi.org/10.1016/j.healthplace.2021.102570

26. van Domelen DR, Koster A, Caserotti P, Brychta RJ, Chen KY, McClain JJ, et al. Employment and physical activity in the U.S. Am J Prev Med 2011;41(2):136-45. https://doi.org/10.1016/j.amepre.2011.03.019

27. Abu-Omar K, Messing S, Sarshar M, Gelius P, Ferschl S, Finger J, et al. Sociodemographic correlates of physical activity and sport among adults in Germany: 1997-2018. German J Exerc Sport Res 2021;51(2):170-82.

28. Sequeira S, Cruz C, Pinto D, Santos L, Marques A. Prevalence of barriers for physical activity in adults according to gender and socioeconomic status. Br J Sports Med 2011:45(15):A18-9.

29. Rütten A, Abu-Omar K, Gelius P, Schow D. Physical inactivity as a policy problem: Applying a concept from policy analysis to a public health issue. Health Res Policy Syst 2013;11(1):9.

30. Amini H, Habibi S, Islamoglu AH, Isanejad E, Uz C, Daniyari H. COVID-19 pandemic-induced physical inactivity: The necessity of updating the Global action plan on physical activity 2018-2030. Environ Health Prev Med 2021;26(1):32. https://doi.org/10.1186/s12199-021-00955-z

31. Martinez EZ, Silva FM, Morigi TZ, Zucoloto ML, Silva TL, Joaquim AG, et al. Physical activity in periods of social distancing due to COVID-19: A cross-sectional survey. Cien Saude Colet 2020;25 suppl 2:4157-68

https://doi.org/10.1590/1413-812320202510.2.27242020

\section{RELATED ARTICLES PUBLISHED IN JHSCI}

1. Đido V, Pilav A, Marjanović M, Phillips J, Švaljug D, Boskovic S, Konjo H, Omerović Đemil. Applicability of the Fels questionnaire on physical activity of children in rural areas of Bosnia and Herzegovina. JHSCI. 2020;10(3):204-10.

2. Pilav A, Rudić A, Branković S, Doder V. Prevalence of behavioral risk factors of non-communicable diseases among urban and rural population in the Federation of Bosnia and Herzegovina. JHSCI. 2014;4(2):83-9. 